\title{
Commentary \\ Debate: Transfusing to normal hemoglobin levels improves outcome
}

Marilyn T Haupt

Oregon Health Sciences University, Portland, Oregon, USA

Correspondence: Oregon Health Sciences University, Critical Care Services, 3181 SW Sam Jackson Park Road, Portland, OR 97201, USA.

Tel: +1 503494 0189; fax: +1 503494 0334; e-mail: hauptm@ohsu.edu

Received: 21 February 2001

Accepted: 28 February 2001

Published: 7 March 2001
Critical Care 2001, 5:64-66

(c) 2001 BioMed Central Ltd

(Print ISSN 1364-8535; Online ISSN 1466-609X)

\begin{abstract}
Red cells are uniquely designed to transport oxygen and facilitate oxygen uptake by systemic tissues. Blood transfusions are thus logical therapeutic choices in patients who exhibit signs of oxygen debt. A small number of studies that have addressed patients with metabolic or physiologic signs of oxygen debt or regional ischaemia suggest that liberal blood transfusion strategies improve outcome. Therefore, armed with an understanding of the variety of clinical presentations characterising oxygen debt, as well as an appreciation of the risks involved, blood transfusions should be considered in all critically ill patients. This includes the consideration of liberalized hemoglobin triggers and hemoglobin thresholds in normal ranges.
\end{abstract}

Keywords: blood transfusion, hematocrit, hemoglobin, ischemia, oxygen debt, oxygen utilisation

\section{Introduction}

The ability of red blood cells to facilitate the journey of oxygen from the atmosphere to the mitochondrion has been repeatedly demonstrated in a vast literature of mammalian physiology. The physical characteristics of red cells and the properties of their contents allow these cells to increase the solubility of plasma for oxygen by about 30fold. In addition, the affinity of red cells for oxygen is modulated by regional acid-base conditions to favor oxygen loading at the pulmonary alveolar capillary interface as well as unloading at the tissue level.

At present there are no clinically available fluids that have the loading, unloading, and carrying properties of blood. Promising oxygen-transporting chemicals such as fluorocarbons and stroma-free hemoglobin solutions are being developed and tested in clinical trials but are not available for routine clinical use $[1,2]$. Clinically available nonsanguinous fluids (colloids and crystalloids) are often used instead of blood because they increase oxygen delivery to systemic tissues by increasing cardiac output. However, these solutions transport much less oxygen than equivalent volumes of blood. In addition, because of their hypooncotic properties, crystalloidal fluids accumulate in interstitial spaces and can lead to impaired pulmonary gas exchange and to edema of other tissues. Although laboratory and clinical data suggest that hematocrits of 50 or greater are associated with decreased systemic oxygen delivery from loading effects of increased viscosity on cardiac ejection, why do we tolerate lower and even subnormal hemoglobin levels in our stressed critically ill patient population, given the superiority of blood as a carrier of oxygen?

\section{Safety issues}

A heightened awareness of the complications of blood transfusions has led clinicians to challenge the need to maintain conventional or normal hematocrit levels in the 
care of critically ill patients. These complications include the transmission of infection (HIV, hepatitis B and C, and bacterial infections) as well as allergic reactions and impairment of the immune response [3,4]. In a recent review of trauma patients, significant decreases in the number of patients receiving transfusions as well as in the number of units used have been observed [5]. These changes were attributed to an increased knowledge of the complications of blood transfusions by managing clinicians.

\section{Negative studies}

Not only is the safety of blood transfusion in question, but the efficacy of this intervention has been challenged. Several recent clinical studies suggest that transfusing critically ill patients to traditional hemoglobin levels might not improve outcome. For example, a large prospective study reported by Hebert et al [6] demonstrated that critically ill patients with various disorders have similar or improved outcomes when a restrictive approach to transfusion (maintaining hemoglobin levels in the range 7.0-9.0 g/dl) was compared with a more liberal approach (maintaining hemoglobin levels in the range $10.0-12.0 \mathrm{~g} / \mathrm{dl}$ ). Several additional studies have documented that restrictive approaches to transfusion are well tolerated in perioperative surgical patients. In a study of patients undergoing hip fracture repair reported by Carson et al [7], no survival advantage could be demonstrated in patients who received postoperative transfusions, including patients with hemoglobin levels of less than $8 \mathrm{~g} / \mathrm{dl}$. Similar findings have been noted in studies of surgical patients undergoing abdominal aortic surgery $[8,9]$ and coronary artery bypass surgery [10].

The results of these studies are compelling and suggest that blood transfusion aiming at traditional hemoglobin levels might not benefit large numbers of critically ill patients. Nevertheless, these studies were not designed to address patients whose regional or global oxygen demands are not satisfied. In addition, most negative studies do not address the age of the transfused blood in the light of observations that blood stored for prolonged periods has decreased oxygen unloading properties [11].

\section{Supportive studies}

Where is the support for the use of blood transfusions in critically ill patients? Does not a basic understanding of the physiology of oxygen utilization lead to the hypothesis that patients with oxygen debt are most likely to benefit from the superior oxygen-carrying capabilities of blood? Conversely, is anyone surprised that blood transfusions seem to be useless or even harmful in critically ill patients who might not have a problem with oxygen utilization, or in perioperative patients who might have only transient oxygen debts?

Indeed, smaller clinical studies suggest that patients who have regional impairments in oxygen utilization have an improved outcome from a liberal approach to blood transfusion. Subsets of patients have been identified who seem to do better with a liberal rather than a restrictive approach to transfusion. In a study reported by Hebert et al [12], improved survival was noted in transfused anemic patients with cardiac disease in comparison with similar patients who had not been transfused. In a study of patients with chronic obstructive pulmonary disease (COPD) and mean hemoglobin levels of $8.7 \pm 0.8 \mathrm{~g} / \mathrm{dl}$, Schonhofer et al [13] reported that weaning off mechanical ventilation was not achieved until hemoglobin levels of $12.0 \mathrm{~g} / \mathrm{dl}$ were achieved with transfused blood. In a subsequent, larger study, these investigators demonstrated that blood transfusion in COPD patients with hemoglobin levels of less than $11.0-12.0 \mathrm{~g} / \mathrm{dl}$ was associated with decreases in both minute ventilation and work of breathing, presumably owing to a salutory effect on the respiratory muscles inefficiently using oxygen [14]. These small clinical studies stress the need to examine outcomes related to blood transfusion in groups of critically ill patients with evidence of systemic or regional oxygen debts.

\section{Stratification according to markers of oxygen debt}

Blood lactate levels, anion gaps, base deficits, $\mathrm{pH}$ and bicarbonate levels are used under appropriate clinical conditions as markers of oxygen debt, especially in patients with clinical signs of circulatory shock. These markers reflect the biochemical changes that ensue when anaerobic metabolism is present. In a small study of septic patients, Gilbert et al [15] demonstrated that elevated lactic acid levels predicted an increase in systemic oxygen consumption in response to transfused blood, a potentially beneficial response. This response was not observed in a comparable group without lactic acidosis. Accordingly, in the study by Hebert et al [6], which included patients with mostly normal lactate levels $(1.8 \pm 1.8 \mathrm{mmol} / \mathrm{l}$ in the restrictive group and $1.8 \pm 2.1 \mathrm{mmol} / \mathrm{l}$ in the liberal group), a failure to observe differences in outcome might have been because neither group had anaerobic metabolism and thus a need for transfused blood.

Admittedly, lactic acid levels lack both sensitivity and specificity as clinical markers of anaerobic metabolism. [16,17]. When compared with lactate levels, values such as anion gaps, base deficits, $\mathrm{pH}$ and bicabonate levels are even less sensitive and specific. Nevertheless, these markers are easy to obtain in the clinical setting in the absence of more available sensitive and specific markers of anaerobic metabolism. Large clinical studies stratifying patients according to these markers and with the appropriate statistical power have the potential to provide relevant results that will help to clarify the role of blood transfusion in the critically ill.

Some investigators have used abnormalities in systemic oxygen extraction ratio, systemic oxygen consumption and 
delivery, mixed venous oxygen saturation and tension as well as the presence of oxygen supply dependence in response to a clinical intervention as surrogate markers for conditions associated with oxygen debt. These values are also lacking in specificity but have led to promising preliminary results. Conrad et al [18] demonstrated in septic shock patients that a low systemic oxygen extraction ratio (less than 24\%) predicted an increase in oxygen consumption in response to blood transfusion. In a recent study of cardiac surgical patients reported by Casutt et al [19], an increase in systemic oxygen uptake in response to blood transfusion was predicted by pre-transfusion oxygen consumption and delivery values.

\section{Stratification according to regional signs of oxygen debt}

Although lactate levels and oxygen-derived values reflect global abnormalities in the utilizaton of oxygen, there is a need to address the value of blood transfusions in patients with regional ischemia. Global parameters might be normal in the face of regional abnormalities in oxygen utilization. In a study reported by Oud and Haupt [20], patients with severe circulatory shock exhibited tonometrically demonstrated splanchnic ischemia that continued after lactic acid and related acid-base measurements were restored to normal levels through resuscitative interventions. Studies evaluating the response of patients with splanchnic ischemia to blood transfusion are warranted. Newer and better methods of detecting cardiac and neurologic ischemia will also increase the opportunities to assess the effects of blood transfusion in patients with coronary and cerebral vascular disease.

\section{Conclusions}

The risks and benefits of blood transfusion need thoughtful consideration for all types of critically ill patients. More focused evaluations of specific patient populations will help to clarify the use of blood transfusions in critically ill patients. In the meantime, special consideration for blood transfusion should be given to patients with clinical and biochemical evidence of oxygen debt. Problems with the unloading properties of stored blood need to be addressed. More liberal hemoglobin or hematocrit triggers should be considered in patients with coronary artery disease, continuing cardiac ischemia, and patients with COPD who are failing to wean off mechanical ventilation. Although more speculative, a liberal approach to blood transfusion should be considered in patients who have signs of brain, splanchnic, or extremity ischemia.

We welcome letters on any aspect or issue covered in this journal. Letters should be under 400 words and include no more than 5 references, one of which should be the article it relates to. Email your letters to editorial@ccforum.com

\section{References}

1. Spence RK: Perfluorocarbons in the twenty-first century: clinical applications as transfusion alternatives. Artif Cells Blood Substit Immobil Biotechnol 1995, 23:367-380.

2. Greenburg AG, Kim HW: Current status of stroma-free hemoglobin. Adv Surg 1998, 31:149-165.

3. Corwin HL: Blood transfusion: first, do no harm. Chest 1999, 116:1149-1150.

4. Ness PM: Transfusion medicine: an overview and update. Clin Chem 2000, 46:1270-1276.

5. Farion KJ, McLellan BA, Boulanger BR, Szalai JP: Changes in red cell transfusion practice among adult trauma victims. J Trauma Injury Infect Crit Care 1998, 44:583-587.

6. Hebert PC, Wells G, Blajchman MA, Marshall J, Martin C Pagliarello G, Tweeddale M, Schweitzer I, Yetisir E: A multicenter, randomized, controlled clinical trial of transfusion requirements in critical care. Transfusion Requirements in Critical Care Investigators, Canadian Critical Care Trials Group. New Engl J Med 1999, 340:409-417.

7. Carson JL, Duff A, Berlin JA, Lawrence VA, Poses RM, Huber EC, O'Hara DA, Noveck J, Strom BL: Perioperative blood transfusion and post operative mortality. J Am Med Assoc 1998, 279: 199-205.

8. Krausz MM, Dennis RC, Utsunomiya T, Grindlinger GA, Vegas AM, Churchill VH Jr, Mannick JA, Valeri DR, Hechtman HB: Cardiopulmonary function following transfusion of three unit of red blood cell products in elective abdominal aortic aneurysmectomy. Ann Surg 1981, 194:616-624.

9. Weisel RD, Dennis RC, Manny J, Mannick JA, Valeri CR, Hechtman HB: Adverse effects of transfusion therapy during abdominal aortic aneurysmectomy. Surgery 1978, 83:682-690.

10. Johnson RG, Thurer RL, Kruskall MS, Sirois C, Gervino EV, Critchlow J, Weintraub RM: Comparison of two transfusion strategies after elective operations for myocardial revascularization. J Thorac Cardiovasc Surg 1992, 104:307-314.

11. Marik PE, Sibbald WJ: Effect of stored-blood transfusion on oxygen delivery in patients with sepsis. J Am Med Assoc 1993, 269:3024-3029.

12. Hebert PC, Wells G, Tweeddale M, Martin C, Marshall J, Pham B Blajchman M, Schweitzer I, Pagliarello G: Does transfusion practice affect mortality in criticallly ill patients? Am J Respir Crit Care Med 1997, 155:1618-1623.

13. Schonhofer $B$, Bohrer $\mathrm{H}$, Kohler D: Blood transfusion facilitating difficult weaning from the ventilator. Anaesthesia 1998, 53: 181-184.

14. Schonhofer B, Wenzel M, Geibel M, Kohler D: Blood transfusion and lung function in chronically anemic paients with severe chronic obstructive pulmonary disease. Crit Care Med 1998, 26:1824-1828.

15. Gilbert EM, Haupt MT, Mandanas RY, Huaringa AJ, Carlson RW: The effect of fluid loading, blood transfusion and catecholamine infusion on oxygen delivery and consumption in patients with sepsis. Am Rev Respir Dis 1986, 34:873-878.

16. Fink MP: Does tissue acidosis in sepsis indicate tissue hypoperfusion? Intens Care Med 1996, 22:1144-1146.

17. Gutierrez G, Wolf ME: Lactic acidosis in sepsis: a commentary. Intens Care Med 1996, 22:6-16.

18. Conrad SA, Dietrich KA, Hebert C, Romero MD: Effect of red cell transfusion on oxygen consumption following fluid resuscitation in septic shock. Circul Shock 1990, 31:419-429.

19. Casutt M, Seifert B, Pasch T, Schmid ER, Turina MI, Spahn DR: Factors influencing the individual effects of blood transfusions on oxygen delivery and oxygen consumption. Crit Care Med 1999, 27: 2194-2200.

20. Oud L, Haupt MT: Persistent gastric intramucosal ischemia in septic patients following resuscitation from shock. Chest 1999, 115:1390-1396. 